\title{
Review of Forging the Golden Urn: The Qing Empire and the Politics of Reincarnation in Tibet
}

by Max Oidtmann.

New York: Columbia University Press, 2018. xvii + 330 pp. ISBN: 9780231184069.

Forging the Golden Urn is the first monograph in English dedicated to the Golden Urn, arguably the most cited yet least studied institution in the history of the Qing's engagement with Tibet. The Golden Urn was a device employed by the Qianlong court in 1792 to help identify the reincarnation of a trülku by means of a lottery. A trülku is a being that can designate its own rebirth by virtue of extraordinary Buddhist cultivation, as well as a central figure in the monastic, social, and economic life of a local Buddhist society. While the most commonly known examples of trülku are the Dalai Lama and the Panchen Lama, on whose lineages contemporary polemics on the Golden Urn have concentrated, Oidtmann's book draws our attention to the device's much wider application in identifying lesser known yet locally important trülku in the Buddhist societies in Qing Inner Asia.

The book challenges many longstanding assumptions about the Golden Urn. It has been assumed, for example, that the Golden Urn was neither widely used nor viewed as legitimate in the Tibetan Buddhist world. This assumption has reinforced the enduring yet debatable narrative of decline and stagnation of the Qing dynasty and its diminishing influence in Tibet in the nineteenth century. However, as Oidtmann demonstrates, from its inception until 1911, when the Qing empire fell, the Golden Urn was used in the recognition of at least eighty reincarnations in Tibet and Mongolia, despite variations in the structure of the ritual and the accompanying regulations (5). Moreover, while the Golden Urn has long been understood as Tibetan or Manchu in nature, Oidtmann identifies its origin in the Ming bureaucratic measure of assigning posts to civil officials by lottery as a means to prevent corruption. The Qing repurposed this Chinese practice, intended to exclude human intervention, in Tibet to prevent oracles from manipulating the recognition of reincarnations.

Oidtmann's discussion of the Golden Urn revolves around three interrelated themes: sovereignty, faith, and law. As he points out, the Qing court considered breaking the Tibetan monopoly over the arts of divination and prognostication, which very much determined the rebirth of trülku, as crucial to its claim of "sovereignty" over Tibet. "Faith," in this case the belief in Tibetan Buddhism, was the religious foundation of Qing imperial rule in Inner Asia. However, an increased overlap of Tibetan and Mongol 
aristocratic clans and major trülku lineages had become a threat to the believers' trust in the religion. Replacing the corrupt oracles with the new, just device-a new "law," as Oidtmann puts it — of the Golden Urn in the identification of reincarnations was intended to restore trust. To further justify the expansion of Qing "colonialism" in Inner Asia, the Manchu court fashioned a legitimizing discourse extolling the legal justice embodied by the supposedly impartial device (154).

The book begins with an informative introduction on Qing-Tibet relations. It then unfolds in three chapters - three "Acts", as Oidtmann presents it—with each showing a different stage of the life of the institution and showcasing how it was employed in Mongolia, Amdo, and Kham. Act I, "The Royal Regulations," probes into the origination of the Golden Urn in 1792 in the context of the Gurkha invasion of Tibet. Oidtmann argues that the Qing desire to intervene in the Tibetan affairs of trülku reincarnation and divination only arose when the oracles prophesied that it would be impossible to defeat the Gurkhas, coupled with the fact that they identified yet another important trülku in an aristocratic family. Qianlong believed that the corrupt divination process had caused a crisis of faith within the Tibetan Buddhist community and that the crisis not only galvanized the Gurkhas into an invasion of Tibet but also would eventually damage the role of Tibetan Buddhism as the foundation of Qing rule over its Inner Asian constituencies if left unattended. The lottery device was thus brought in from the Ming bureaucracy as a countermeasure to the crisis.

Act II, "Shamanic Colonialism," analyzes the 1793 campaign orchestrated by the Qing court to discredit the Dalai Lama and the oracles among the Buddhist community, triggered by the search for the reincarnation of Erdeni Pandita, a powerful trülku lineage heading a network of monasteries in Mongolia. Oidtmann draws our attention to the Qing court's understanding of Tibetan oracles as a less worthy, less efficacious counterpart to the shamans of China proper, and hence something to be rectified-a mentality that can be read as a variation of similar phenomena in European colonialism, as suggested by the title of this chapter. Eventually, among many other trülku lineages, a non-noble child was identified as the Erdeni Pandita. That identification took place through the Golden Urn under the Qing's close supervision. It confirmed the device's legitimacy and set the precedent for its later application.

Act III, "Amdowas Speaking in Code," reconstructs the 1797 identification of the third reincarnation of the Jamyang Zhepa, the founding lama of Labrang Monastery, which was one of the largest and most influential monasteries in the region of Amdo. Using both secret reports in Manchu by Qing officers stationed in Tibet and Tibetan chronicles, Oidtmann uncovers Qing efforts to ensure that the lottery device was used and that the child favored by the local community in Labrang was not chosen. An important finding in this chapter is the role of the Tibetans: the Tibetan elites, whom earlier scholarship assumed to be consistently resistant to the Qing intervention in 
reincarnation affairs, played a major role in the legitimization of the Golden Urn by producing an extensive literature that found the device a place in Tibetan traditional divination culture and served to justify both the means and the result.

In order to reconstruct the life of the Golden Urn, the author delves into a complex web of agents in Qing-Tibet relations and makes extensive use of historical materials in Manchu, Tibetan, and Chinese languages from both published and unpublished collections. Particularly impressive is his use of the copies of the Manchu-language Palace Memorials housed in the First Historical Archives in Beijing, the published Yonghegong archives, and Tibetan biographies and chronicles. While the Manchu-language government documents show how the Qing court's innermost circle designed and implemented the new institution, the Tibetan material reveals the other side of the story and speaks to the Tibetan response to the Qing intervention, both of which contribute to our understanding of how the practice actually unfolded on the ground. Oidtmann also does an excellent job of guiding the reader through these perhaps less than familiar linguistic and cultural landscapes to produce a remarkably concise and engaging book.

The book may leave readers with a background in legal history wanting a clearer treatment of how the Golden Urn as "law" contributes to the broader discussion of Qing and Chinese legal history more generally. The same goes for the author's discussion of "sovereignty" and its implications in Qing foreign relations, which the book does not quite address. Readers will appreciate the book's unique focus on divination technology. I wonder, however, if the subject matter would not benefit from further discussion in conjunction with the Qing's unprecedented involvement with the Tibetan administration and the Trans-Himalayan region during the contemporary QingGurkha War (1788-1792), which played a more central role in shaping the Qing's new Tibet policy than the book would suggest.

These quibbles aside, rescuing the history of the Golden Urn from the still young but deeply entrenched nationalist narratives of both PRC and the Tibetan diaspora alone is a significant contribution, and the book is a must-read for anyone interested in Qing-Tibet relations.

Lei Lin 林蕾, Harvard University 
